\title{
Tomografia de coerência óptica em osteoma de coróide: relato de caso
}

\author{
Optical coherence tomography in choroidal osteoma:case report
}

\author{
Mário Junqueira Nóbrega ${ }^{1}$ \\ Cristina Martins Faria Bortolotto ${ }^{2}$
}

Trabalho realizado no Hospital de Olhos Sadalla Amin Ghanem. Joinville (SC).

${ }^{1}$ Mestre e Doutor pela Universidade Federal de São Paulo (UNIFESP). São Paulo (SP). Professor de Oftalmologia na Universidade da Região de Joinville (UNIVILLE). Joinville (SC). Oftalmologista do Hospital de Olhos Sadalla Amin Ghanem. Joinville (SC).

2 Oftalmologista do Hospital de Olhos Sadalla Amin Ghanem. Joinville (SC).

Endereço para correspondência: Mário Junqueira Nóbrega - Rua Abdon Batista, 172 - Joinville (SC) CEP 89201-010

E-mail: mjn@terra.com.br

Recebido para publicação em 29.03.2004

Versão revisada recebida em 29.09.2004

Aprovação em 16.06.2005

\begin{tabular}{|c|}
\hline RESUMO \\
\hline Os autores apresentam um caso de osteoma de coróide diagnosticado em \\
paciente do sexo masculino aos 62 anos de idade. A lesão bem delimitada e \\
pouco elevada no pólo posterior do olho direito acompanhada de vasculari- \\
zaçãointerna e neovascularização de coróide em sua borda temporal superior \\
e inferior levaram à suspeita do tumor. O diagnóstico de certeza foi obtido \\
com ecografia A e B e tomografia computadorizada. A tomografia de \\
coerência óptica mostrou alta refletividade em toda a espessura do osteoma \\
bem como elevação do complexo EPR-cório-capilarna região da membrana \\
neovascular subretiniana. Embora os achados tomográficos descritos na \\
literatura e os observados neste caso sejam variados, a tomografia de \\
coerência óptica pode colaborar no diagnóstico de osteoma de coróide. \\
\hline
\end{tabular}

Descritores: Osteoma de coróide; Tomografia de coerência óptica; Ecografia; Neovascularização de coróide; Relatos de casos [tipo de publicação]

\section{INTRODUÇÃOO}

Osteoma de coróide é um tumor benigno constituído de tecido ósseo maduro. É raro, unilateral em $75 \%$ dos casos e mais prevalente em mulheres. Seu diagnóstico geralmente é feito na $2^{\underline{a}}$ e 3 a década de vida ${ }^{(1)}$.

Clinicamente, apresenta-se como lesão amarelo-clara ou alaranjada, bem delimitada, de forma variável, localizada no pólo posterior. Seu diâmetro e espessura alcançam valores máximos de $22 \mathrm{~mm}$ e $2,5 \mathrm{~mm}$, respectivamente. Pode-se observar, em muitos casos, vascularização profunda no interior do tecido ósseo. Neovascularização de coróide é complicação frequiente em osteoma de coróide ${ }^{(2-4)}$.

O diagnóstico baseia-se no exame clínico, na ecografia A e B e na tomografia computadorizada. A ecografia é típica e evidencia hiperrefletividade na superfície do tumor e silêncio acústico posterior a ele. A tomografia computadorizada mostra imagem radiopaca de densidade óssea no pólo posterior do olho afetado ${ }^{(1-2)}$.

A tomografia de coerência óptica (OCT) é um método de avaliação nãoinvasivo que fornece detalhes precisos da arquitetura da retina e cório-capilar. Sua aplicação em osteoma de coróide ainda é pouco descrita na literatura ${ }^{(5-6)}$.

O objetivo do trabalho é relatar um caso de osteoma de coróide que também foi avaliado através de tomografia de coerência óptica.

\section{RELATO DO CASO}

Paciente de 62 anos, do sexo masculino, procedente de Itapema (SC) procurou o Hospital de Olhos Sadalla Amin Ghanem em 10/9/2004 devido à 
baixa visual no olho direito percebida, por acaso, cerca de 10 meses antes da consulta. $\mathrm{O}$ exame oftalmológico realizado por outro profissional, na época, evidenciou lesão macular direita de caráter irreversível e, por este motivo, não realizou qualquer tratamento e deixou de fazer novas avaliações neste período. Não havia antecedentes pessoais oculares e sistêmicos significantes. Não havia história familiar de doença ocular séria.

O exame oftalmológico mostrava acuidade visual corrigida de 20/300 no olho direito e 20/20 no olho esquerdo. A biomicroscopia apresentava-se normal em ambos os olhos e a pressão intra-ocular era $15 \mathrm{mmHg}$ no olho direito e $14 \mathrm{mmHg}$ no olho esquerdo.

A fundoscopia evidenciava, no olho direito, lesão de mácula e feixe papilo-macular amarelo-clara bem delimitada, de diâmetro aproximado de $4 \mathrm{~mm}$ e discretamente elevada. Havia tufos vasculares no interior da área e, no seu setor temporal superior, havia lesão acinzentada, elevada, acompanhada de hemorragia subretiniana e descolamento neuro-sensorial de retina; observava-se também outra lesão acinzentada e mal delimitada junto à borda temporal inferior da mácula (Figura 1A). Não existiam alterações fundoscópicas no olho esquerdo.

A angiofluoresceinografia retiniana mostrava lesão macular com hipofluorescência em fase precoce e hiperfluorescência heterogênea em fase avançada. Havia vazamento do contraste no setor temporal superior e temporal inferior da lesão, com bloqueio da fluorescência na região da hemorragia subretiniana; isto caracterizou a presença de neovascularização de coróide nas duas áreas adjacentes à mácula.

A ecografia A e B apresentava lesão pouco elevada do pólo posterior, com alto pico acústico em sua superfície interna e sombra acústica orbitária posterior a ela (Figura 2A).

A tomografia computadorizada orbitária mostrava pequena imagem radiopaca na região posterior do olho direito, lateralmente à inserção do nervo óptico (Figura 2B).

Através dos exames complementares, confirmou-se o diagnóstico clínico de osteoma de coróide com presença de membrana neovascular subretiniana junto à sua borda temporal superior e inferior.
Realizada a tomografia de coerência óptica, com múltiplos cortes no interior do tumor, observou-se espessamento do complexo EPR-cório-capilar, de alta refletividade, bem delimitado, com as seguintes dimensões: diâmetro horizontal $=3,35 \mathrm{~mm}$, diâmetro horizontal $=4,49 \mathrm{~mm}$ e espessura $=240$ micra. Não se verificaram alterações estruturais retinianas sobre a lesão. $\mathrm{Na}$ porção superior ao tumor, observou-se elevação bem delimitada do complexo EPR-cório-capilar, de moderada refletividade e também se constatou descolamento da retina neuro-sensorial nas regiões temporal superior e temporal inferior ao tumor (Figura 1B).

\section{DISCUSSÃO}

As finalidades de relatar o presente caso de osteoma de coróide são enfatizar a importância do exame clínico associado à ecografia ocular e tomografia computadorizada e avaliar a tomografia de coerência óptica como adjuvante no seu diagnóstico.

A princípio, pensou-se que se tratasse de ampla cicatriz disciforme no pólo posterior do olho direito. A idade do paciente, bem acima da observada em casos de osteoma de coróide recentemente diagnosticado, e a presença da membrana na borda temporal superior e inferior reforçava, de certa maneira, a suspeita clínica. Porém, a utilização da biomicroscopia de fundo mostrou detalhes de vascularização interna e discreta elevação da lesão que motivaram a avaliação complementar.

A ultra-sonografia ocular e a tomografia computadorizada foram imprescindíveis para o diagnóstico de osteoma de coróide. Elas mostraram características típicas de deposição de cálcio na região afetada.

Já a tomografia de coerência óptica, método de avaliação cada vez mais utilizado em doenças retinianas e glaucoma, foi empregada com a finalidade de se obterem detalhes de sua arquitetura que pudessem corroborar o diagnóstico e ser comparados com estudos publicados.

Segundo Ide et al, a avaliação pela OCT de 3 pacientes com
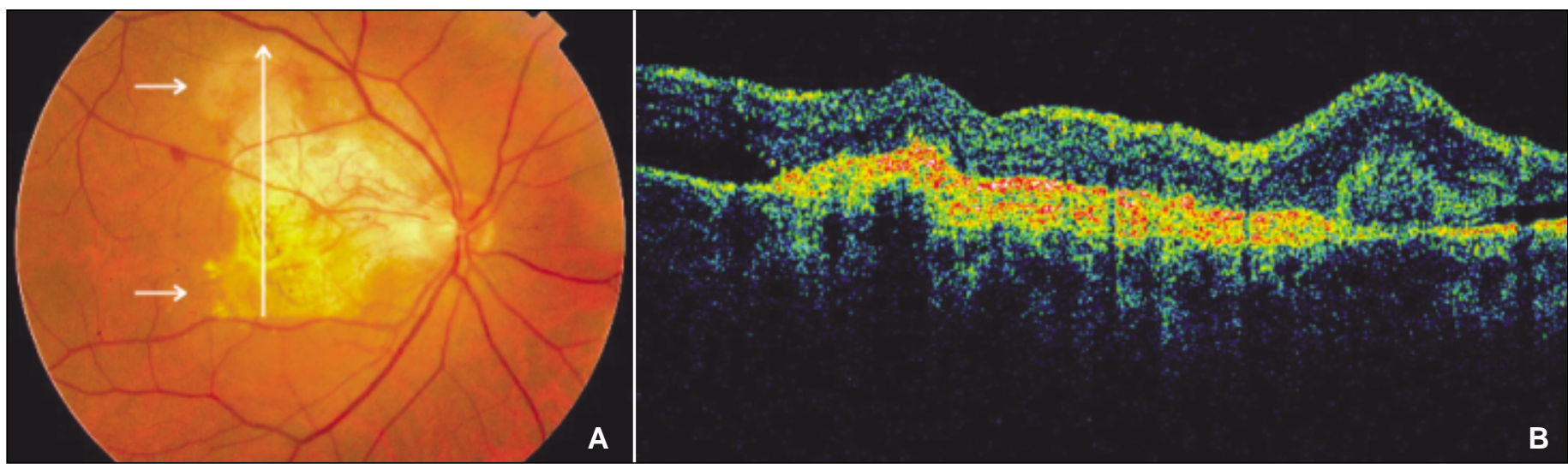

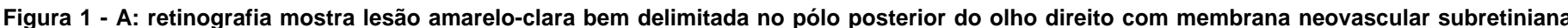

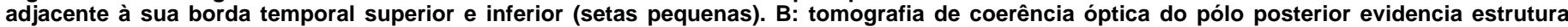

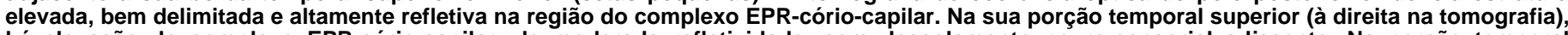

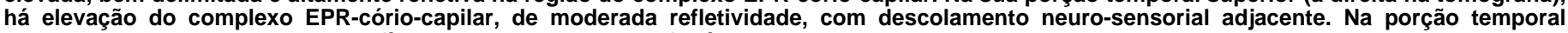
inferior (à esquerda na tomografia) há descolamento neuro-sensorial adjacente ao tumor 


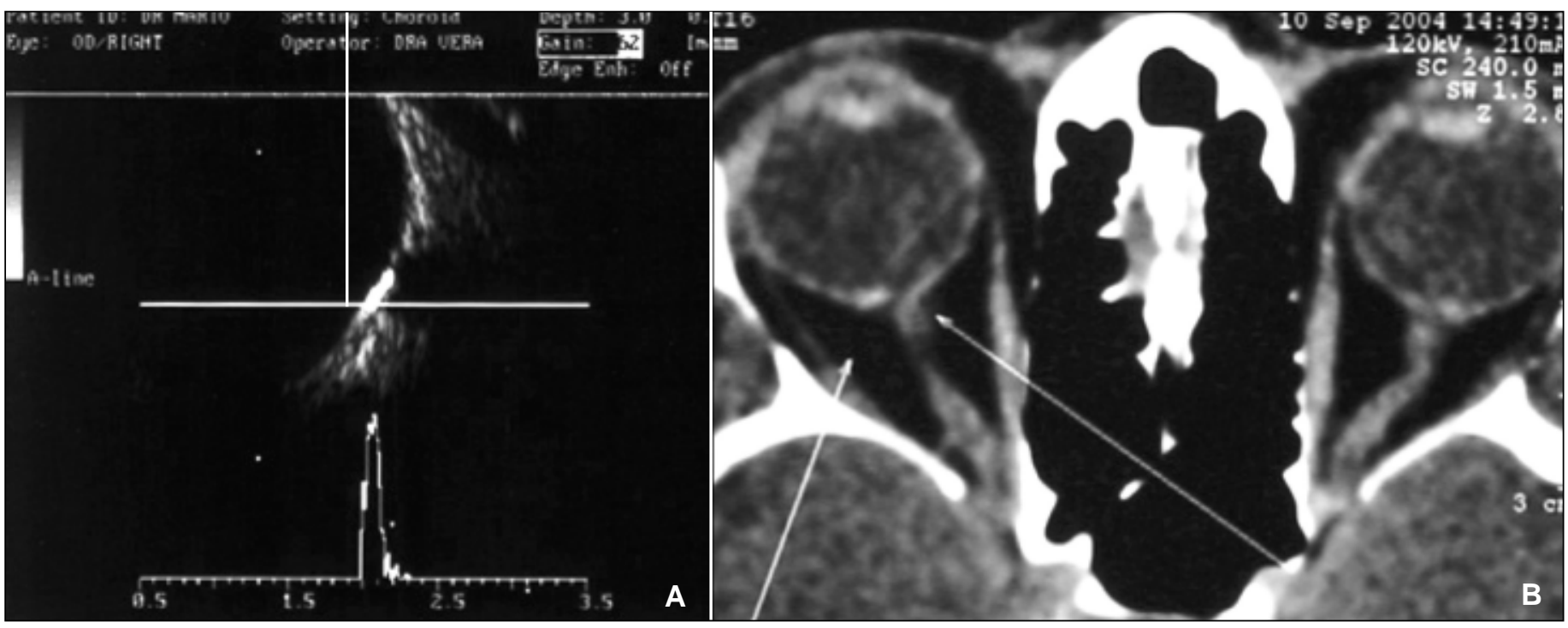

Figura 2 - A: aspecto ecográfico mostra pico de alta refletividade na superfície interna e sombra acústica orbitária posterior ao tumor. B: tomografia computadorizada evidencia imagem radiopaca de densidade óssea, lateralmente à inserção do nervo óptico no olho direito

osteoma de coróide mostrou dois padrões distintos de refletividade: um caracterizado por múltiplos caminhos de alta refletividade posteriores à superfície tumoral e outro caracterizado por lesão irregular em forma de placa com aumento de refletividade junto à coróide ${ }^{(5)}$.

Por outro lado, Fukasawa e Iijima observaram sinais de alta refletividade juntos à presença de estruturas cavernosas em região de atrofia do epitélio pigmentado retiniano (EPR). Como na área de EPR preservado não se detectaram as estruturas cavernosas, os autores concluíram que há diferentes padrões de refletividade interna dependentes da evolução da ossificação e de características do EPR sobrejacente ${ }^{(6)}$.

No presente caso, o aspecto tomográfico mostrou aumento de refletividade em toda a espessura do osteoma, com o aspecto de placa, sob o epitélio pigmentado retiniano. Não se observaram, entretanto, áreas que sugerissem formação de cavernas no interior do tumor.

\section{CONCLUSÃO}

Conclui-se que a OCT é um método complementar no diagnóstico do osteoma de coróide. Provavelmente, à medida que novos casos forem relatados, outros padrões de refletividade e arquitetura interna serão identificados conforme características estruturais do tumor, da coróide e do EPR.

\section{AGRADECIMENTOS}

À Dra. Veralúcia Rosa Ferreira e ao Dr. Evandro Luís Rosa, do Setor de Ultra-sonografia Ocular e Angiofluoresceinografia Retiniana do Hospital de Olhos Sadalla Amin Ghanem e ao Dr. José Francisco Jannini, do Centro de Tomografia do Hospital Municipal São José, de Joinville.

\section{ABSTRACT}

The authors present a case of choroidal osteoma diagnosed in a 62-year-old male patient. A well-defined and slightly elevated lesion located in the posterior pole of the right eye associated with internal vasculature and choroidal neovascularization at its superior and inferior temporal edge were suspicious of the tumor. Confirmation of diagnosis was obtained with A and B ecography and computed tomography. Optical coherence tomography showed high reflectivity through its thickness as well as elevation of the RPE-choriocapillaris complex at the choroidal neovascularization site. Although the literature and the present case show several different tomographical findings, optical coherence tomography can help establishing the diagnosis of choroidal osteoma.

Keywords: Choroidal osteoma; Optical coherence tomography; Ecography; Choroidal neovascularization; Case reports [publication type]

\section{REFERÊNCIAS}

1. Shields CL. Choroidal osteoma. In: Guyer DR, Yanuzzi LA, Chang S, Shields JA, Green WR, editors. Retina-Vitreous-Macula. Philadelphia: WB Saunders; 1999. p.1092-102.

2. Shields CL, Shields JA, Augsburger JJ. Choroidal osteoma. Surv Ophthalmol. 1988;33(1):17-27. Review.

3. Gass JD. New observations concerning choroidal osteomas. Int Ophthalmol. 1979;1(2):71-84

4. Coston TO, Wilkinson CP. Choroidal osteoma. Am J Ophthalmol. 1978; 86(3):368-72.

5. Ide T, Ohguro N, Hayashi A, Yamamoto S, Nakagawa Y, Nagae Y, Tano Y. Optical coherence tomography patterns of choroidal osteoma. Am J Ophthalmol. 2000;130(1):131-4.

6. Fukasawa A, Iijima H. Optical coherence tomography of choroidal osteoma. Am J Ophthalmol. 2002;133(3):419-21. 